\title{
Rates of Presurgical Underestimation of Breast Cancer after Standardized Assessment of Breast Calcifications
}

\section{Raten präoperativer Unterschätzung von Brustkrebs bei standardisierter Abklärung von Mikroverkalkungen der Brust}

Authors

Affiliations
L. Timpe ${ }^{1}$, S. Berkemeyer ${ }^{1}$, M. Puesken ${ }^{1}$, J. Tio ${ }^{2}$, W. Heindel ${ }^{1}$, S. Weigel ${ }^{1}$

Department of Clinical Radiology and Reference Center for Mammography, University Hospital Muenster, Germany

2 Department of Gynecology and Obstetrics, University Hospital Muenster, Germany

\author{
Key words \\ - breast \\ - breast cancer \\ - biopsy breast \\ - ultrasound \\ - vacuum-assisted biopsy \\ - quality assurance
}

$\begin{array}{ll}\text { received } & 29.9 .2014 \\ \text { accepted } & 22.2015\end{array}$

Bibliography

DOI http://dx.doi.org/

10.1055/s-0034-1399273

Published online: 15.4.2015

Fortschr Röntgenstr 2015; 187:

445-449 @ Georg Thieme

Verlag KG Stuttgart · New York .

ISSN 1438-9029

\section{Correspondence \\ PD Dr. Stefanie Weigel}

Institut für Klinische Radiologie, Universitätsklinikum Münster Albert-Schweitzer-Campus 1 48149 Münster

Germany

Tel.: ++49/0251/8345650

Fax: ++ 49/0251/8345660

weigels@uni-muenster.de

\section{Zusammenfassung \\ $\nabla$}

Ziel: Häufigkeitsbestimmung histopathologischer Brustkrebsunterschätzung nach Vakuumsaugbiopsie (VSB) in der standardisierten Abklärung von Mikroverkalkungen der Brust im Vergleich zur postoperativen Diagnose.

Material und Methoden: Die retrospektive Studie schließt konsekutiv akquirierte Daten von 506 Frauen ein, bei denen eine VSB in der Abklärungsdiagnostik reiner Mikroverkalkungen nach standardisierter digitaler mammografischer und sonografischer Bildgebung durchgeführt wurde. Bei 119/506 Frauen folgte eine weitere chirurgische Intervention: bei 37 in Form einer offenen diagnostischen Exzision, bei 82 basierend auf einem therapeutischen Konzept. Die histopathologischen Ergebnisse der präoperativen VSB wurden mit den postoperativen histopathologischen Befunden verglichen.

Ergebnisse: Bei 91/119 Frauen (76,5\%) war die endgültige Histologie maligne. Der Anteil des duktalen Carcinoma in situ (DCIS) betrug 79,1\% (72/91), der Anteil der invasiven Karzinome 20,9\% (19/91). Bei 9/37 Frauen mit diagnostischen Exzisionen änderte sich die präoperative benigne bzw. unklare Dignität zu einer postoperativen malignen Diagnose (24,3\%). In acht Fällen betraf die Diagnoseunterschätzung das DCIS $(21,6 \%)$ und in einem Fall invasiven Brustkrebs $(2,7 \%)$. Sieben von neun unterschätzte Fälle $(77,8 \%)$ resultierten aus der diagnostischen Exzision atypischer epithelialer Proliferationen vom duktalen Typ (AEPDT, positiver prädiktiver Wert $30,4 \%(7 / 23))$. Bei präoperativer DCIS-Diagnose wurde bei $7 / 71$ Frauen postoperativ invasiver Brustkrebs diagnostiziert (9,9\%). Bei 11/82 Frauen mit einer onkologisch geplanten Operation wurde invasiver Brustkrebs bereits durch die VSB diagnostiziert.

Schlussfolgerung: Die präoperative Unterschätzung einer DCIS-Diagnose nach VSB bei postope-

\section{Abstract \\ $\nabla$}

Purpose: To determine the frequency of histopathological underestimation of breast cancer after vacuum-assisted biopsy (VAB) in standardized assessment of breast calcifications compared to postsurgical diagnosis.

Materials and Methods: The retrospective study included acquired data of 506 consecutively examined women, who underwent VAB for the assessment of pure calcifications after standardized digital mammographic and sonographic imaging. $119 / 506$ (24.5\%) women underwent further surgical procedures: 37 women had a surgical diagnostic excision biopsy, 82 women a surgical procedure based on a therapeutic concept. Presurgical results of VAB were compared with the postsurgical histopathological reports.

Results: In 91/119 women (76.5\%) the final histology was malignant. The rate of ductal carcinoma in situ (DCIS) was $79.1 \%$ (72/91) and the rate of invasive carcinoma was $20.9 \%$ (19/91). In 9/37 women with diagnostic excision biopsy, the presurgical status of benign or uncertain changed to a postsurgical diagnosis of malignant (24.3\%). In eight cases underestimation included DCIS (21.6\%) and in one case invasive cancer (2.7\%). Seven of the nine underestimated cases $(77.8 \%)$ resulted from excision biopsy of atypical epithelial proliferation of ductal type (AEPDT, positive predictive value $30.4 \%(7 / 23)$ ). After surgery due to DCIS in $7 / 71$ women invasive breast cancer was diagnosed (9.9\%). In 11/82 women with oncological surgery, invasive cancer was already diagnosed by VAB.

Conclusion: Underestimation of invasive cancer in terms of presurgical DCIS diagnosis can be minimized by the standardized assessment protocol to about $10 \%$. Underestimation of DCIS is mainly related to presurgical diagnosis of AEPDT. 
rativ nachgewiesenem invasiven Mammakarzinom kann durch das standardisierte Abklärungsprotokoll auf etwa $10 \%$ minimiert werden. Die Unterschätzung des DCIS kommt vor allem bei der präoperativen Diagnose atypischer Proliferationen vom duktalen Typ vor.

Kernaussagen:

- Der standardisierte Einsatz digitaler mammografischer und sonografischer Bildgebung vor Durchführung der Vakuumsaugbiopsie ist geeignet, die Unterschätzung des invasiven Brustkrebses zu minimieren. AEPDT stellen eine Hochrisikodiagnose hinsichtlich einer Unterschätzung des DCIS dar.
Key Points:

- The standardized use of digital mammographic and sonographic imaging prior to vacuum-assisted biopsy is suitable for minimizing underestimation of invasive breast cancer. AEPDT represents a high risk diagnosis for underestimation of DCIS.

Citation Format:

- Timpe L., Berkemeyer S., Puesken M. et al. Rates of Presurgical Underestimation of Breast Cancer after Standardized Assessment of Breast Calcifications. Fortschr Röntgenstr 2015; 187: 445-449

\section{Purpose}

$\nabla$

Previous reports have focused on lesion-related and device-related factors influencing underestimation after percutaneous biopsy in relation to postsurgical histology [1] defined as an upgrade of a benign lesion or a lesion with an uncertain malignant potential to a malignant diagnosis or upgrade of a diagnosis of ductal carcinoma in situ (DCIS) to invasive breast cancer. Underestimation of DCIS occurs more frequently with large-core biopsy than with vacuum-assisted biopsy (VAB) [2]. Further risk factors are high-grade lesion at diagnostic excision biopsy, lesion size greater than $20 \mathrm{~mm}$ in diameter at radiological imaging, palpability and mammographic masses [1].

In the course of the establishment of digital mammography techniques, the detection rate of breast lesions corresponding with calcifications increased [3]. VAB is the method of choice in the invasive assessment of calcifications. Because of a known association of small invasive breast cancers as well as DCIS, a precursor lesion of invasive breast cancer, with calcifications, VAB is a frequently used diagnostic tool in the assessment of mammography screening programs [4]. Therefore, the accuracy of presurgical histological results plays an important role in daily clinical practice in terms of adequate surgical planning, risk assessment regarding postsurgical changes to malignancy and informed discussion.

Therefore, we determined the frequency of underestimation of postsurgical histopathological results in comparison to presurgical histopathological diagnosis of vacuum-assisted biopsy in standardized assessment of pure breast calcifications.

\section{Materials and Methods}

$\nabla$

\section{Study group}

The retrospective study included acquired data of 506 consecutively examined women, who underwent VAB for the assessment of pure calcifications after participation in one digital unit of the national mammography screening program [5, 6] within 30 months (January 2010 to June 2013).

After VAB, correlation between imaging characteristics and histopathological morphology was proven in all cases by a multidisciplinary conference.

In 382 of 506 women (75.5\%) after VAB no further surgical procedure was recommended. 358 of these VABs were coded with the histopathological category B2 (benign lesions: cystic alterations, adenosis $n=298$, fibroadenoma $n=51$, fat necrosis $n=6$, periductal mastitis $n=3$ ) and 24 were coded with B3 (lesions of uncertain malignant potential: lobular neoplasia $n=16$, small papilloma re- moved $n=4$, small radial scar not depicted by imaging $n=4$ ) as described by the European guidelines [5].

Follow-up of women with B2 lesions without recommended surgery was available for 305 of 358 women (85.2\%) as follows: 221 women had a normal screening mammogram two years later, 84 women had follow-up examinations after biopsy at the hospital during the screening interval; invasive breast cancer $\leq 10 \mathrm{~mm}$ in size was diagnosed in one woman in a different quadrant to the performed VAB at an interval of 15 months. Follow-up of women with B3 lesions without recommended surgery was available for 22 of 24 women (91.7\%) with the following results: 15 women had a normal screening examination two years later, 7 women had an individual follow-up scheme with shorter intervals than two years; no cancer occurred. No follow-up was available in 55 women (with B2 lesions $n=53$, with B3 lesions $n=2$ ).

In 124 of 506 women (24.5\%) after VAB further surgical procedures were indicated. In 119 of 124 women (96.0\%) surgery was performed and data were available for evaluation. 37 of 119 women (31.1\%) underwent a surgical diagnostic excision biopsy. Diagnostic excisions were indicated due to histological risk lesions $(n=36)$ or a histological benign lesion in the assessment of linear calcifications $(n=1)[5,7]$ ( $\triangle$ Table 1$) .82$ of 119 women $(68.9 \%)$ had a surgical procedure based on a therapeutic concept ( $\bullet$ Table 1$)$.

\section{Standardized assessment of calcifications}

Assessment took place at a specialized breast diagnostic unit at a university hospital. Two breast radiologists performed standardized additional imaging procedures for the assessment of calcifications, including digital magnification views cranio-caudal and latero-medial (Selenia, Dimensions; Hologic, Bedford, Mass) [8] and high-resolution ultrasound (Acuson S2000; Siemens Healthcare, Erlangen, Germany). Clinical examination and ultrasound of the whole breast were added systematically to verify the absence of an associated mass as well as to assess the axillary lymph nodes. With knowledge of additional imaging and clinical examination during the assessment process, radiologists documented the lesion morphology in the screening software (MaSc; KVIT, Dortmund, Germany). Calcifications without an additional mass, identified by described imaging, were called pure calcifications. For study purposes lesion data were extracted from the screening software. Diameters of areas of suspicious calcifications were estimated on the magnification views pre-VAB. In cases of pure suspicious calcifications, vacuum-assisted biopsy was performed by two breast radiologists ( $9 \mathrm{G}$, mean number of samples 12 , range 7 to 20). Post-biopsy mammograms cranio-caudal and lateromedial were obtained. Samples were examined by two specialized pathologists. Lesions were categorized according to the $\mathrm{B}$ categories as described by the European guidelines ( $\bullet$ Table 1 ). 
Table 1 Distribution of pathological B categories and histological lesions after performance of vacuum-assisted biopsy of women with further recommendation for surgical procedure.

Tab. 1 Verteilung der pathologischen B Kategorien und der histologischen Läsionen nach durchgeführter Vakuumsaugbiopsie von Frauen mit weiterführender operativer Empfehlung.

\begin{tabular}{|c|c|c|}
\hline $\begin{array}{l}\text { category of vacuum- } \\
\text { assisted biopsy }\end{array}$ & histological lesion & $\begin{array}{l}\text { number| } \\
\text { frequency } \\
\mathrm{N} /(\%)\end{array}$ \\
\hline B2: benign lesion & adenosis $^{1}$ & $1(0.8)$ \\
\hline \multirow[t]{5}{*}{$\begin{array}{l}\text { B3: lesions of uncertain } \\
\text { malignant potential }\end{array}$} & $\begin{array}{l}\text { atypical epithelial prolif- } \\
\text { eration of ductal type }\end{array}$ & $21(17.6)$ \\
\hline & papillary lesion ${ }^{3}$ & $9(7.6)$ \\
\hline & radial scar ${ }^{3}$ & $2(1.7)$ \\
\hline & mucocele-like lesion ${ }^{3}$ & $1(0.8)$ \\
\hline & flat epithelial atypia ${ }^{3}$ & $1(0.8)$ \\
\hline $\begin{array}{l}\text { B4: suspicious of malig- } \\
\text { nancy }\end{array}$ & $\begin{array}{l}\text { atypical epithelial prolif- } \\
\text { eration of the ductal type, } \\
\text { suspicious for ductal carci- } \\
\text { noma in situ }\end{array}$ & $2(1.7)$ \\
\hline $\begin{array}{l}\text { B5a: malignant, in situ } \\
\text { lesion }\end{array}$ & ductal carcinoma in situ & $71(59.7)$ \\
\hline $\begin{array}{l}\text { B5b: malignant, } \\
\text { invasive breast lesion }\end{array}$ & invasive breast cancer & $11(9.2)$ \\
\hline total & & $119(100)$ \\
\hline \multicolumn{3}{|c|}{$\begin{array}{l}1 \text { Histologically benign lesion in the assessment of linear calcifications, correlation was } \\
\text { based on non-comedo calcifications in dilated ducts; surgery revealed that the DCIS } \\
\text { had a weak correlation of DCIS with calcifications. } \\
\text { Histologisch gutartige Läsion resultierend aus der Abklärung linearer Mikroverkal- } \\
\text { kungen, die Korrelation basierte auf Non-Komedonekrosen in dilatierten Gängen; die } \\
\text { Operation erbrachte, dass das DCIS eine schwache Mikrokalkkorrelation aufwies. } \\
{ }^{2} \text { Diagnostic excision biopsy was indicated independently of residual parts of the lesion } \\
\text { by imaging. } \\
\text { Diagnostische Exzisionen wurden unabhängig von mammografischen Restverkal- } \\
\text { kungen indiziert. } \\
{ }^{3} \text { Diagnostic excision biopsy was indicated if residual parts of the lesion were suspected. } \\
\text { Diagnostische Exzisionen wurden in Abhängigkeit von residualen Befunden indiziert. }\end{array}$} \\
\hline
\end{tabular}

All biopsy results were confirmed for agreement between radiological and pathological diagnosis in a multidisciplinary conference [5]. If indicated, therapeutic or diagnostic surgery was planned by the multidisciplinary team. According to our previously described diagnostic protocol, all lesions of atypical epithelial proliferation of ductal type (AEPDT) were recommended for surgical excision. Diagnostic excision was recommended for radial scars (RS), papillary lesions (PAP), mucocele-like lesions (MUC) and flat epithelial atypia (FEA) when lesion remnants were visible on post-interventional imaging [7].

\section{Analysis}

Histopathological diagnosis after surgery was compared with presurgical histopathological diagnosis of VAB. Underestimation of histological breast lesions after $\mathrm{VAB}$ in comparison to further surgery was defined as follows:

- Diagnostic excision biopsy: A histologically benign lesion or a lesion of uncertain malignant potential obtained by VAB changed postsurgery to a malignant histology, including DCIS and invasive breast cancer.

- Therapeutic surgery: A DCIS diagnosis obtained by VAB changed postsurgery to an invasive breast cancer diagnosis.

The rates of underestimation were determined separately for diagnostic excision biopsy and therapeutic surgery. In each case, the presurgical result of VAB was compared with the postsurgical histopathological report.
Table 2 Distribution of histopathological pre- and postsurgical lesions of performed diagnostic excision biopsies.

Tab.2 Verteilung histopatholgischer prä- und postoperativer Diagnosen durchgeführter offener diagnostischer Exzisionen.

\begin{tabular}{|c|c|c|c|}
\hline $\begin{array}{l}\text { histological } \\
\text { lesion }\end{array}$ & $\begin{array}{l}\text { planned } \\
\text { diagnostic } \\
\text { excision } \\
\text { surgery }\end{array}$ & $\begin{array}{l}\text { underesti- } \\
\text { mation }\end{array}$ & $\begin{array}{l}\text { underesti- } \\
\text { mation per } \\
\text { lesion type }\end{array}$ \\
\hline & $\begin{array}{l}\text { number } \\
\mathrm{N}\end{array}$ & $\begin{array}{l}\text { number } \\
\mathrm{N} / \text { (pT category) }\end{array}$ & $\begin{array}{l}\text { frequency } \\
\%\end{array}$ \\
\hline adenosis & 1 & 1 (pTis) $^{1}$ & 100 \\
\hline $\begin{array}{l}\text { atypical epi- } \\
\text { thelial prolif- } \\
\text { eration of } \\
\text { ductal type }\end{array}$ & 23 & $\begin{array}{l}6(\mathrm{pTis})^{2} \\
1(\mathrm{pT} 1 \mathrm{a})^{3}\end{array}$ & 30.4 \\
\hline $\begin{array}{l}\text { papillary } \\
\text { lesion }\end{array}$ & 9 & 1 (pTis) ${ }^{4}$ & 11.1 \\
\hline radial scar & 2 & 0 & 0 \\
\hline $\begin{array}{l}\text { mucocele-like } \\
\text { lesion }\end{array}$ & 1 & 0 & 0 \\
\hline $\begin{array}{l}\text { flat epithelial } \\
\text { atypia }\end{array}$ & 1 & 0 & 0 \\
\hline total & 37 & 9 & 24.3 \\
\hline
\end{tabular}

PT: pathological tumor category according to the TNM classification.

PT: pathologische Tumorkategorie entsprechend der TNM-Klassifikation.

${ }^{1}$ Ductal carcinoma in situ, nuclear grade: intermediate $(n=1)$.

Duktales carcinoma in situ, Kernmalignitätsgrad: intermediär $(n=1)$.

${ }^{2}$ Ductal carcinoma in situ, nuclear grade: low $(n=2)$, intermediate $(n=2)$, high $(n=2)$.

Duktales carcinoma in situ, Kernmalignitätsgrad: gering $(n=2)$, intermediär $(n=2)$,

hoch $(\mathrm{n}=2)$.

${ }^{3}$ Invasive ductal carcinoma, grade: 2

Invasiv duktales Karzinom, Grad: 2.

${ }^{4}$ Ductal carcinoma in situ, nuclear grade: low $(n=1)$.

Duktales carcinoma in situ, Kernmalignitätsgrad: gering $(n=1)$.

Sizes of areas of suspicious calcifications on magnification views pre-VAB were measured to calculate the median and range. Post$\mathrm{VAB}$ the mammographic complete versus incomplete removal of calcifications was determined.

\section{Results}

In 91 of 119 women undergoing surgery (76.5\%), the final histology was malignant. Among these diagnoses, the rate of ductal carcinoma in situ (DCIS) was $79.1 \%(72 / 91)$ and the rate for invasive carcinoma was $20.9 \%(19 / 91)$.

\section{Diagnostic excision biopsy}

Of the 37 women who had a diagnostic excision biopsy, the presurgical benign diagnosis was confirmed in 28 cases (75.7\%). In 9 of 37 women the final diagnosis was underestimated and the presurgical non-malignant diagnosis changed to a postsurgical malignant diagnosis $(24.3 \%)$. Of these nine cases, underestimation included the diagnosis of DCIS (mean $9 \mathrm{~mm}$, range 5 $32 \mathrm{~mm}$ ) in eight cases $(21.6 \%$ ) and the diagnosis of an invasive cancer of $5 \mathrm{~mm}$ in size in one case $(2.7 \%)$. Seven of the nine underestimated cases $(77.8 \%)$ resulted from excision biopsy after the diagnosis of atypical epithelial proliferation of ductal type (AEPDT). The positive predictive value for malignancy of AEPDT was $30.4 \%(7 / 23)$ ( $\bullet$ Table 2$)$.

In the case of atypical epithelial proliferation of ductal type, the median mammographic diameter of calcifications without 
Table 3 Distribution of histopathological pre- and postsurgical lesions of performed oncological surgeries.

Tab.3 Verteilung histopatholgischer prä- und postoperativer Diagnosen durchgeführter onkologischer Operationen.

\begin{tabular}{|c|c|c|c|}
\hline \multirow[t]{2}{*}{$\begin{array}{l}\text { histological } \\
\text { lesion }\end{array}$} & $\begin{array}{l}\text { planned oncolo- } \\
\text { gical surgery }\end{array}$ & underestimation & $\begin{array}{l}\text { underestima- } \\
\text { tion per lesion } \\
\text { type }\end{array}$ \\
\hline & $\begin{array}{l}\text { number } \\
\text { N/(pT category) }\end{array}$ & $\begin{array}{l}\text { number } \\
\text { N/(pT category) }\end{array}$ & $\begin{array}{l}\text { frequency } \\
\%\end{array}$ \\
\hline $\begin{array}{l}\text { ductal carci- } \\
\text { noma in situ }\end{array}$ & 71 & $\begin{array}{ll}7 \quad(\text { pT1a } n=3)^{1} \\
\\
(\text { pT1b } n=3)^{2} \\
(\text { pT2 } n=1)^{3}\end{array}$ & 9.9 \\
\hline $\begin{array}{l}\text { invasive } \\
\text { breast cancer }\end{array}$ & $11 \quad \begin{array}{r}(\text { pT1a } n=6) \\
(\text { pT1c } n=5)\end{array}$ & - & - \\
\hline total & 82 & & \\
\hline
\end{tabular}

${ }^{1}$ Invasive ductal carcinoma, grade $1(n=2)$; invasive lobular carcinoma, grade $1(n=1)$. Invasiv duktales Karzinom, Grad $1(n=2)$; invasiv lobuläres Karzinom, Grad $1(n=1)$.

2 Invasive ductal carcinoma, grade $2(n=2)$, grade $3(n=1)$.

Invasiv duktales Karzinom, Grad $2(n=2)$, Grad $3(n=1)$

${ }^{3}$ Invasive ductal carcinoma, grade $2(n=1)$.

Invasiv duktales Karzinom, Grad $2(n=1)$.

a postsurgical upgrade $(n=16)$ was $15 \mathrm{~mm}$ (range $3 \mathrm{~mm}$ to $50 \mathrm{~mm})$, and that of those with a postsurgical upgrade $(\mathrm{n}=7)$ was $28 \mathrm{~mm}$ (range $4 \mathrm{~mm}$ to $51 \mathrm{~mm}$ ). In 2 of 10 (20.0\%) AEPDT diagnoses without residuals calcifications post-VAB, an upgrade occurred postsurgically, while 5 of 13 (38.5\%) AEPDT diagnoses with residual calcifications had a postsurgical upgrade.

\section{Oncological surgery}

In 11 of the 82 women who received oncological surgery, an invasive cancer was already diagnosed by VAB. Postsurgical diagnoses included invasive ductal carcinoma $(n=9)$, invasive lobular carcinoma $(n=1)$ and invasive micropapillary carcinoma $(n=1)$. In 71 women surgery was planned on the base of a presurgical DCIS diagnosis. After surgery due to DCIS, invasive breast cancer was diagnosed in 7 of those 71 women (9.9\%) and the pre-surgical result underestimated the presence of invasion (mean diameter $11 \mathrm{~mm}$, range $2-37 \mathrm{~mm}$ ). In $28.6 \%(\mathrm{n}=2)$ of the underestimated cases, the nuclear grade was reported as intermediate, and in $57.1 \%(n=4)$ as high. In one case the nuclear grade was not available (14.3\%) ( Table 3 ).

The median mammographic diameter of calcifications of DCIS cases without a postsurgical upgrade $(n=64)$ was $24 \mathrm{~mm}$ (range $4 \mathrm{~mm}$ to $96 \mathrm{~mm})$. Among the DCIS cases with an upgrade $(\mathrm{n}=7)$, the median mammographic diameter of calcifications was $36 \mathrm{~mm}$ (range $7 \mathrm{~mm}$ to $79 \mathrm{~mm}$ ).

Of all VAB-related DCIS diagnoses, underestimation occurred in 2 of 16 cases (12.5\%) of mammographic lesion size over $50 \mathrm{~mm}$.

In 2 of 15 DCIS lesions (13.3\%) without residual calcifications post-VAB, an upgrade occurred postsurgically (pT1a, pT1b). In 5 of 56 DCIS lesions (8.9\%) with residual calcifications post-VAB, an upgrade was diagnosed postsurgically.

\section{Discussion}

$\nabla$

Standardized assessment of mammographic pure breast calcifications with exclusion of an associated mass by ultrasound and consecutive performance of vacuum-assisted biopsies underestimated final histological lesions of diagnostic excision biopsies in
$24 \%$ of cases, so that postsurgical modification of histology required oncological surgery. The leading constellation consisted of postsurgical DCIS diagnosis after excision biopsy due to atypical epithelial proliferation of ductal type resulting from vacuumassisted biopsy. In primary DCIS diagnoses obtained by vacuumassisted biopsy, $90 \%$ were estimated precisely whereas in $10 \%$ of cases presurgical invasive breast cancer was underestimated.

The assessment of breast calcifications resulted in 28 benign (23.5\%) and 91 malignant (76.5\%) postsurgical diagnoses. Postsurgical malignancy should be monitored, especially since calcification-related breast lesions are known to be associated with higher rates of lesions of uncertain malignant potential (B3) than masses [9] and therefore may carry a higher probability for a benign surgical excision compared to masses or a mixture of mammographic lesion types.

Similarly to previous results, we found AEPDT to be the B3 lesion with the highest rate of finally detected malignancy (40\% [7], $50 \%$ [10]). $30.4 \%$ (7/23) of the diagnoses of AEPDT in minimally invasive biopsy were not proved as atypical ductal hyperplasia $(\mathrm{ADH})$ after excision surgery but were upgraded to a malignant diagnosis, mainly to DCIS diagnosis (85.7\%). Kohr et al. concluded that surgical excision should be recommended even when ADH involves fewer than three foci and all mammographic calcifications have been removed by needle biopsy, because the upgrade rate was still $12 \%$ [11]. Our results support that finding.

Brennan et al. performed a meta-analysis of the underestimation of invasive breast cancer with ductal carcinoma in situ at needle biopsy. The pooled estimate was $25.9 \%$. Preoperative variables that showed significant univariate association with higher underestimation included the use of a 14-gauge core biopsy device versus the use of an 11-gauge vacuum-assisted biopsy with an underestimation of $30.3 \%$ versus $18.9 \%(P<.001)$, respectively [1]. Our results, using a 9-gauge device, show an underestimation of $10 \%$. Underestimation occurs in constellation with and without residual calcifications post-VAB. The low rate of underestimation may not only be related to the large biopsy device. The meta-analysis defined risk constellations for underestimation as palpable versus impalpable lesions, presence of mammographic masses versus the absence and stereotactic image guidance of biopsy versus ultrasound or clinical guidance. Our study collective was restricted to cases of pure calcifications. The absence of associated masses was proved by additional magnification imaging and ultrasound. Therefore, we suppose that the standardized imaging protocol was useful to select cases of low risk for underestimation.

After DCIS diagnosis in VAB, the multidisciplinary team has to define a recommendation for surgery including breast surgery and facultative axillary staging by sentinel lymph node biopsy. Guidelines recommend sentinel lymph node biopsy in cases of presurgical DCIS diagnoses and planned mastectomy $[12,13]$. For our above described collective without stratification of lesion size or nuclear grade, the risk of underestimation of invasion did not exceed $10 \%$ so that a general recommendation of a sentinel lymph node biopsy in combination with a breast-conserving biopsy in terms of a DCIS diagnosis and sonographicaly normal axillary lymph nodes does not seem adequate. Kotani et al. concluded that because of a low prevalence of metastatic involvement, the cessation of SLNB is a reasonable consideration in patients initially diagnosed with DCIS by stereotactic VAB [14]. In concordance, the American Society of Clinical Oncology recently updated a clinical practice guideline and recommends that women with DCIS should not undergo SLNB when breast-conserving surgery is planned [12]. 
Nevertheless, constellations with higher probabilities for invasion of over $50 \%$ for palpable lesions should be carefully evaluated by the multidisciplinary team regarding axillary staging $[1,15]$. SLNB may be considered as part of the primary surgical procedure when preoperative variables show a tumor larger than $2 \mathrm{~cm}[1,16]$. The national working group of gynecological oncologists suggests discussion of sentinel lymph node biopsy in the planning of a breastconserving therapy only for cases of DCIS lesions $\geq 5 \mathrm{~cm}$ or $>2.5 \mathrm{~cm}$ in combination with high grade subtypes [13]. Our data support that restrictive recommendation since invasive cancer was underestimated in only about $13 \%$ of all DCIS lesions $\geq 5 \mathrm{~cm}$, resulting in a secondary recommendation of SLNB.

Despite dedicated imaging before biopsy and the use of large devices, invasive cancer, mostly less than $10 \mathrm{~mm}$ in size (85.7\%), was still underestimated in $10 \%$ of all VAB-related DCIS diagnoses. The frequency of upgrade was comparable for cases with total removal of calcifications by $\operatorname{VAB}(13.3 \%)$. Our study provides a risk estimation which might also be useful for presurgical dialog with patients. In addition, MRI may be a useful tool in mammography screening assessment [17-19].

The strengths of our study are that results are based on a standardized procedure with high quality assurance: clearly defined guidelines, specially trained radiologists and pathologists. Furthermore, we exclusively used direct radiography digital magnification techniques and high-resolution breast ultrasound.

A limitation of the study is due to the fact that we analyzed data of one assessment unit only. The possibility to transfer the results is limited. Due to the limited number of cases, we did not evaluate subgroups of risk estimation by statistical tests.

\section{Conclusion}

\section{$\nabla$}

Underestimation of DCIS (21.6\%) in diagnostic excision biopsies is mainly related to presurgical diagnosis of AEPDT. Underestimation of invasive cancers in diagnostic excision biopsies is rare (2.7\%). Underestimation of invasive cancer in terms of presurgical DCIS diagnosis can be minimized (9.9\%) by standardized assessment protocols including mammographic and sonographic imaging prior to vacuum-assisted biopsy.

\section{Acknowledgemts}

$\nabla$

The authors would like to thank Ms. Stefanie Michalk for the administrative help provided.

\section{Clinical relevance}

The establishment of digital mammography in breast cancer screening identified and clarified microcalcifications more often compared to the currently outdated analogue mammography technique. Protocols define vacuum-assisted biopsy as the method of choice for assessment of microcalcifications. The accuracy of a preoperative diagnosis compared to the postoperative end diagnosis is relevant for patient counseling, for planning of surgery - especially with the objective to minimize follow-up surgeries, and for the indication of sentinel lymph node biopsy. The integration of additional digital mammography views and high-resolution ultrasound imaging can achieve a selection of low risk for non-identification of invasive breast cancer after vacuum-assisted biopsy.

\section{References}

1 Brennan ME, Turner RM, Ciatto S et al. Ductal carcinoma in situ at coreneedle biopsy: meta-analysis of underestimation and predictors of invasive breast cancer. Radiology 2011; 260: 119-128

2 Jackman R, Burbank F, Parker SH et al. Stereotactic breast biopsy of nonpalpable lesions: determinants of ductal carcinoma in situ underestimation rates. Radiology 2001; 218: 497 - 502

3 Del Turco MR, Mantellini P, Ciatto S et al. Full-field digital versus screenfilm mammography: comparative accuracy in concurrent screening cohorts. Am J Roentgenol 2007; 189: 860-866

4 Weigel S, Decker T, Korsching E et al. Calcifications in digital mammographic screening: improvement of early detection of invasive breast cancers? Radiology 2010; 255: 738 - 745

5 Perry $N$, Broeders $M$, de Wolf $C$. eds. European guidelines for quality assurance in breast cancer screening and diagnosis. 4th ed. Luxembourg: Office for Official Publications of the European Communities; 2006

6 Bundesmantelvertrag. Ärzte/Ersatzkassen über besondere Versorgungsaufträge im Rahmen des Programms zur Früherkennung von Brustkrebs durch Mammographie-Screening. Anlage 9.2 Versorgung im Rahmen des Programms zur Früherkennung von Brustkrebs durch Mammographie-Screening. Deutsches Ärzteblatt 2004; 4: 16-44

7 Weigel S, Decker T, Korsching E et al. Minimal invasive biopsy results of "uncertain malignant potential" in digital mammography screening: high prevalence but also high predictive value for malignancy. Fortschr Röntgenstr 2011; 183: $743-748$

8 Fallenberg EM, Dimitrijevic L, Diekmann F et al. Impact of Magnification Views on the Characterization of Microcalcifications in Digital Mammography. Fortschr Röntgenstr 2014; 186: 274-280

9 Hungermann D, Weigel S, Korsching E et al. Diagnostics of microcalcifications from minimally invasive biopsies in mammography screening: results from the prevalence phase. Pathologe 2009; 30: 31 - 35

10 Rakha EA, Lee AH, Jenkins JA et al. Characterization and outcome of breast needle core biopsy diagnoses of lesions of uncertain malignant potential (B3) in abnormalities detected by mammographic screening. Int J Cancer 2011; 129: 1417-1424

11 Kohr JR, Eby PR, Allison KH et al. Risk of upgrade of atypical ductal hyperplasia after stereotactic breast biopsy: effects of number of foci and complete removal of calcifications. Radiology 2010; 255: 723 - 730

12 Lyman GH, Temin S, Edge SB et al. Sentinel lymph node biopsy for patients with early-stage breast cancer: American Society of Clinical Oncology clinical practice guideline update. J Clin Oncol 2014; 32: $1365-1383$

13 Arbeitsgemeinschaft Gynäkologische Onkologie (AGO). Diagnostik und Therapie primärer und metastasierter Mammakarzinome, Ductales Carcinoma in situ (DCIS), Online Aktualisierung 27.3.2014 Guidelines of the AGO Breast Committee Guidelines Breast Version 2014.1. www.ago-online.de/fuer-mediziner/leitlinienempfehlungen/mamma/

14 Kotani H, Yoshimura A, Adachi Y et al. Sentinel lymph node biopsy is not necessary in patients diagnosed with ductal carcinoma in situ of the breast by stereotactic vacuum-assisted biopsy. Breast Cancer 2014, Epub ahead of print

15 Schulz S, Sinn P, Golatta M et al. Prediction of underestimated invasiveness in patients with ductal carcinoma in situ of the breast on percutaneous biopsy as rationale for recommending concurrent sentinel lymph node biopsy. Breast 2013; 22: $537-542$

16 Son BK, Bong JG, Park SH et al. Ductal carcinoma in situ and sentinel lymph node biopsy. J Breast Cancer 2011; 14: 301 - 307

17 Breast Imaging Working Group of the German Radiological Society Updated Recommendations for MRI of the Breast. Fortschr Röntgenstr 2014; 186: $482-483$

18 Bick $U$, Engelken F, Diederichs $G$ et al. MRI of the Breast as Part of the Assessment in Population-Based Mammography Screening. Fortschr Röntgenstr 2013; 185: 849-856

19 Wisner DJ, Hwang ES, Chang CB et al. Features of occult invasion in biopsy-proven DCIS at breast MRI. Breast J 2013; 19: 650-658 